\title{
The Support to Improve Self-efficacy and Healing of Drugs Addict
}

\author{
Rosdiana $^{1}$, Bhisma Murti ${ }^{2}$, Mahendra Wijaya ${ }^{3}$, Suwarto $^{4}$ \\ ${ }^{1,4}$ Doctoral Program, Sebelas Maret University, Indonesia \\ ${ }^{2}$ Medicine Faculty, Sebelas Maret University, Indonesia \\ ${ }^{3}$ Social Politics Faculty, Sebelas Maret University, Indonesia
}

\begin{tabular}{l} 
Article Info \\
\hline Article history: \\
Received Sep 19, 2016 \\
Revised Nov 20, 2016 \\
Accepted Nov 26, 2016 \\
\hline
\end{tabular}

\section{Keyword:}

Peer support

Self-efficacy

Drugs addict

\begin{abstract}
Appropriate counseling and education can be adopted to achieve a change in attitude, knowledge and perception. Still there is a wrong perception of a given intervention. Peer support through a process of social learning, the process of growing understanding of how to process information from experience, observational include: attention (attention), given (retention), reproduction of motion (reproduction), motivation (motivation), and communication. The purpose of this study was to analyze resident selfefficacy to regardless of drug addiction through family support. This study employed qualitative approach with case study design. Subjects in this study were residents, ex drugs user, peer support, and resident family. The results showed that peer support from fellow residents and the support of the major on duty (MOD) very meaningful and helpful for resident in the healing process.
\end{abstract}

Copyright $(2) 2016$ Institute of Advanced Engineering and Science. All rights reserved.

\section{Corresponding Author:}

Rosdiana,

Department of Public Health,

Student of Doctoral Program, Sebelas Maret University, Indonesia.

Email: anahanur@gmail.com

\section{INTRODUCTION}

Appropriate counseling and education can be adopted to achieve a change in attitude, knowledge and perception. Still there is a wrong perception of a given intervention [1]. Peer support through a process of social learning, the process of growing understanding of how to process information from experience, observational include: attention (attention), given (retention), reproduction of motion (reproduction), motivation (motivation), and communication. With the support of peers who do the sharing of experience, then the learning process [2]. Narcotics and drugs are concerned in East Kalimantan. Target of drug syndicates not only children but also teenagers of school. During late adolescence, alcohol use tends to rise to the top [3]. Standard demands of work from the company became more commonplace for workers. Overtime work up to 18 hours to make special interests using narcotics [4], the assumption can help become stronger and vibrant [5] 1 and persisted over time [6].

East Kalimantan has a population of 42 million, and recorded the number of drug users reached $3.1 \%$ of the total population, equivalent to 79600 people. Samarinda is the number one city highest narcotics cases in East Kalimantan and the second-ranked city in Indonesia after Jakarta. Samarinda is prone city, not just a path narcotics but also existing Narcotics factory at Guerrilla and Jelawat Street in 2012, and successfully raided by security forces.

Appropriate counseling and education can be adopted to achieve a change in attitude, knowledge and perception. Still there is a wrong perception of a given intervention [1]. Peer support through a process of social learning, the process of growing understanding of how to process information from experience, observational include: attention (attention), given (retention), reproduction of motion (reproduction), 
motivation (motivation), and communication. With the support of peers who do the sharing of experience, then the learning process [2].

Samarinda has first-class educational support group that carried out by non-governmental organizations (NGOs), and rehabilitation organized by the government. Professional institutions can help build formal and informal support [7]. The activity provides communication, information, counseling and education about the dangers of narcotics, benefits and effects when using the drug regularly. Implementation education class with peer support group, presenting models of addicts have managed to escape from drug addiction, resulting in the sharing process. Peer influence and relations have implications for the prevention of the use of narcotics [8].

Activity is already available and implemented in both the public and private sectors but not significant. This is evidenced by the increase in the numbers of drug users annually. For that they need the support and assistance in adding a place of rehabilitation and social support with different shades such as religion or a vocational approach.

\section{RESEARCH METHOD}

This was a qualitative study with case study strategy. This conducted in National Narcotics Agency Province (Badan Narkotika Nasional Provinsi, (BNNP)) and County National Narcotics Agency (Badan Narkotika Kabupaten (BNNK) Samarinda, East Kalimantan.

Respondents in this study came from three subjects over which users or former drug users, peer support, and family support. Furthermore, based on data from previous respondents have informants who knew and associated with both existing rehabilitation programs in government agencies (BNNK and BNNP) as well as from non-governmental in Samarinda (LSM barrel). The sampling was purposive sampling technique. It continued using Snowball Sampling (sample Snowball). Data collection techniques with indepth interviews (in-depth interview), study the documentation, and observation. The stages of data analysis, data reduction, the data display and conclusion /verification [9] are shown in Figure 1.

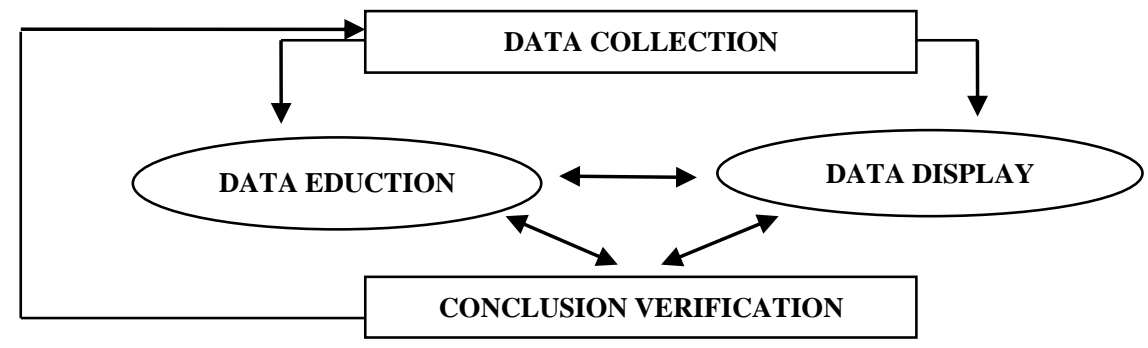

Figure 1. Interaction pattern data analysis research (Miles and Huberman, 2000)

\section{RESULTS AND ANALYSIS}

\subsection{Results}

Peer support is a system of giving and receiving assistance which is based on the key principles of respect of shared responsibility and mutual agreement on giving full assistance [10]. The purpose of giving peer support is to encourage and support the former addict to stay motivated to break free from drug addiction and prepare for all possibilities that could affect relapse (relapse) and a positive attitude towards all the obstacles and challenges faced during the process of recovery. There are several forms of peer support in helping change behavior separated from drug addiction. The first is the emotional support as in the following quote:

\subsubsection{Instrumental support}

Instrumental support refers to the supply of goods or services that can be used to solve practical problems. This support helps individuals to carry out their activities. This type of support in the form of aid that is tangible and immediate which can be a service, time and helps the task a person when you're stressed. Based on observations instrumental support authors performed by the resident in Tanah Merah rehabilitation centers on the influence of peer support in helping to escape from drug addiction in the form of: 
a. Instrumental support in a loan of money.

Instrumental support in borrowing money is not valid in rehabilitation centers Tanah Merah. It is set within walking paper Resident order no 14 "are prohibited from accepting and storing money, food in the dorm." Resident only focus on recovering from drug addiction by following all of the rehabilitation program in rehab centers without having to even think about the money issue.

Quotations 1:

"If ordinary motor can wash 7,000 or 10,000 thousand rupiah if Make a food reward outstanding 10,000 or 20,000 rupiah"

b. Instrumental support in the form of loans goods

Borrowing instrumental support in the form of goods is also not allowed in the hall rehabilitation Tanah Merah.

Quotations 2:

"It's hard miss, if you want to borrow items must be used the same license at all resident miss."

c. Food and Services

Instrumental support in the form of sharing food also has its own rules. Food and supplies as well as the needs of the resident are already provided by rehabilitation centers Tanah Merah.

\subsubsection{Support information}

Support this includes provision of advice, guidance, suggestions, or feedback on what has been done.

a. Support information in the form of advice

Support in the form of suggestions received by the resident is in rehab at Tanah Merah rehabilitation centers varies, depending on the needs of each resident. For example in the home detox, usually resident needs is advice or a solution for them to survive endure the pain and keep the spirit of being home to undergo detox program, and can go up to move home to move on to the next program. Houses stabilization or also called the period of hurricanes. This is a difficult time also for the resident for a period of adaptation of organs without the narcotic substances that enter the body within a period of 2 weeks- 3 months. The house has a primary system privileges for new family coming in or join.

b. Support information in the form Feedback / Feedback

Feedback is one-dimensional domain in the information support. Support information is applied in the form of counseling process. Each resident get a counselor, and has scheduled two meetings with each counselor in one week.

Quotations 3:

"A lot of things help him, when I was in primary I feel upset because there divorce decisions come out and my wife had also returned to her village. Bro, Kiky have given me encouragement, advice and so on. Counseling with Kiky, make we feel comfortable just to vent, until things really my secret sharing all to him. "

In fact, the counseling process is not running optimally in rehabilitation centers Tanah Merah. This is due to the small number of personnel rehab counselor who owned the hall, so that the counselors have 17 to 20 children guidance. Based on interviews with informants:

Quotations 4:

"Yes it was, many child guidance miss, so if we need for counseling, because it has not accommodated our schedule and our though, sometimes unfocused program run it, until a lot of friends who give fumble. Sometimes when we turn to consul he has not in good mood, likened have the problem stale."

\subsubsection{Emotional support}

Emotional support is done by involving the expression of empathy, concern, and attention to someone that gives a feeling of comfort, peace of heart, and feeling loved that made him feel better. Based on the research that has been done, there is some form of peer support in helping change behavior separated from drug addiction. Emotional support can be in the form:

a. Caring

Emotional support in the form of mutual care in rehabilitation centers have been set in the system, especially at primary home. For example there is a new resident comes, then another resident who was a senior will be selected by a major on duty to take responsibility for assisting new resident and teach all the rules in the house (buddy system). Little Body have to ask any questions he does not understand and have to follow wherever his buddy away, the distance between buddy and little body could not exceed 2 meters. Based on interviews of informants: 
Quotations 5:

"Huuft ... shocked miss, initially excited because moving house, that means in a minute left, so happy, fit up the stairs end and stepped on the floor, it felt like the building collapsed, because suddenly a lot of people who came up with the shouting and screaming loudly..... really miss. hиии not frivolous feelings and thoughts, borax anyway, do not know what to do next."

b. Love each other and feel kinship.

Other peer support in the form of emotional support in the form of mutual love and feel kinship which appear curiosity resident helping others because they feel have the same fate as those who depend on narcotics.

Quotations 6:

"miss her family, here strong family relationships between residents, help each other in case warned not punished for failing, entertaining if sad, support each other well in carrying out everyday tasks.

Reinforcing mutually is desperate".

In addition, if there are resident or family who need something like armor because of shortages, underwear, razors and others, usually the forum, so that family feel redundant or can be used with a variety of family in need.

Quotations 7:

"Yes once, then I find it really miss, when I come here bring his one, please heck parents or relatives who come visit all brought clothes, was until now no one has brought. Friends even major collect it on shirts and pants that fit for me, and now I have a lot of shirts and pants for the help of friends".

\subsubsection{Support on self-esteem}

This support occurs through positive expression of appreciation for the individuals concerned, drive forward and a positive comparison of individuals with others. Oxford (1992) 5 found support for the award focused on the existence of a recognition, a positive assessment, and acceptance of the individual. Results informant interviews:

Quotations 8:

"No miss, I am the person oblivion is sometimes forget pen, forget return it tool function in place, and a lot of things miss often I forget, at the meeting agenda PAGE, and my bad habits are discussed, shame miss, but at PAGE this also never made me really happy and feel tutu me still has a. buck up meaning for others, because it can thank caution of all the family on my craft and creativity".

Support on self-esteem also exists in the form of encouragement. This is proven through observation and interviews of the resident.

Quotations 9:

"Mutual support is also in performing daily tasks and mutually reinforcing if desperate".

b. Mutual Respect Opinion

Support on self-esteem also exists in the form of mutual respect opinions. Mutual opinion respect usually applied at the time of the discussion in the forum in the form of activities such as morning meetings, medicine, seminar competition to ascend the stage, closing house, and many other activities that require sheering opinion or discussion to integrate perception and mind so drawn one conclusion to be implemented together. Based on observation, respect the opinion at the time atmosphere and accompanied by a major forum on duty runs as it should.

Quotations 10:

"Never, miss annoying ...... once with the A ... he was a senior and we were crew chef always ruled, scolded, do not get enough fumble give to us, we-we are just tired of always he who give fumble, a little bit of a friend can fumble from him again-he again, until his face was going to throw clay, suppose outside had me beat it out, basic junky ... .junky ... "

\subsubsection{Social supports}

This type of support is given by creating the conditions for a person to feel part of a group that has a common interest and social activities. Support from former users or peer support that has managed to recover and successful future for and accepted by the social environment is in need to escape from drug addiction.

a. Interest

Able to fight addiction, resistant to the temptation to go back to using drugs, can receive family environment, social environment, given this opportunity and confidence by people in a work order to set the future direction the better, it can be useful to the family of the Nation's is the dream of a resident who underwent rehabilitation program in the hall. To achieve these desires rehabilitation centers Tanah Merah has a rehabilitation program that is the concept of the Therapeutic Community (TC) program combined with 
Narcotics anonymous (NA). But in implementation, vocational or personal development, vocational training and interest resident inadequately accommodated due to lack of means of infrastructures and human resources support in the rehabilitation centers. This is proved by the results of the interview on informants as follows:

Quotations 11:

" complicated miss, jumbled, happy, sad, confused, anxiety also exists. Glad because like everywhere you can, as here, right limited miss, if out there be free and happy because of meet old man also with unlimited time again. Confused I do not know what can I face my problem that's out there, before I signed here the loads miss my problems out, as my debt with a friend, confused on how to set forth my efforts were bankrupt. Sadly for have no wife and children at home, I'm home alone later wrote home. I cannot finish my problems out there later, worrying seized again when the b. Activity make and had to go here again imagine miss must sign in here again".

Tanah Merah rehabilitation centers, Samarinda targeting six months for patients addict (resident) narcotics to "heal". All activities are guided by the system of house of hope, is a home-based therapy programs therapeutic community (TC) and combined with a 12-step program and it is believed that it can help each other and themselves to stay clean using 12 traditions, four structures program, five milestone in the pillar and foundation program 12 step program, and are obliged to profess the Creed clicking the end of each meeting. Solid activity quite tiring resident, based on interviews with informant's result:

Quotations 12:

"Hooooo ...... began to get up at 4:30 the morning until 9 o'clock to sleep again that sometimes stretch to $10 \mathrm{pm}$ no breaks, all the jobs are pressed for time, break nicotine wrote that there seemed to be relaxed, but just briefly, the rest hooo ... .cape physical and mind, so if you've closing house entered the dorm and go to bed immediately asleep, until said snoring-replication".

Quotations 13:

"Serious miss, if you have tired and bored often also our jokes, for example through the floor and meet friends should communicate but we replace you paint, or we pretended to be busy when the function, often we take the journal friends were presented in order to go up the stage, so no need to bother to create and the more we make that funny, bored too seriously continue miss".

Based on observations, not all courses in the house of hope is run properly and correctly according to the standard implementation of the 12-step model of change of attitudes and NA 12 steps. Results of interview with informants:

Quotations 14:

"Nice combination does the program but has not been effective in its implementation, so that the results are not maximized."

Activities there are only about bike washing, preparing instant noodles, make drinks such as coffee / milk, the living brewed, this activity that they consider the project. Based on interviews with some of the resident:

Quotations 15:

"Saturated really, miss, see for yourself the morning breakfast / smoke time, morning meeting at $08.00 \mathrm{pm}$, after the schedule are non-search projects on the entire staff / employees in the Hall of rehabilitation such as the washing of motor, make instant noodle / food, coffee / milk, washing clothes. Otherwise there is a request has not finished project, hanging idle, dah bored hanging out to go to sleep, then hanging out again".

This is what makes the current resident is scheduled to return home, they find anxiety, confused, insecure and even fear because of lack of preparation themselves. Activity that is in the house does not support the re-entry in repairman mindset that the resident is ready to get back in the middle of the community.

\subsection{Discussion}

Implementation of the program through peer support between resident to resident, and between the resident and the resident MOD prepared to make fully involved in each activity, according to his job function each-each. Position the clerk just as a supervisor, who oversees the program. Category structure of the main program of the Therapeutic Community Empowerment peer support work in order to minimize the influence of pressure or stress experienced by the resident. In other words, if there is no pressure or stress of peer support during the social rehabilitation program at home primary, then the program does not affect the efficacy within the resident. There are 10 counselors who concurrently becomes MOD is a former drug addict. So that the process of social rehabilitation enough to help residents, Passing of the learning process where the resident teaching and learning to follow their exemplary (role modeling). 
According to the World Health Organization (WHO) (in consensus, 2002), a person is said to be recovering from drug addiction when they are free or clean from drugs for at least two years. Not all drug addicts managed to recover and got his ex-addicts. Getting ex-users it is an incredible success, as it has struggled to run through a variety of temptations that can lead to relapse. And is able to remain established steadfast in the midst of many difficulties he faced. The experience of success facing the many difficulties remained clean of narcotics, which would MOD / counselor for the resident. Besides from that experience as well MOD / counselor many understand the attitude of manipulation Resident Program is carried out while undergoing rehabilitation.

Unit therapy and rehabilitation used by Tanah Merah rehabilitation is a Therapeutic Community (TC) meaning "a group of people who have the same problem, they come together to help each other in overcoming the problems encountered, in other words the man helping man to help himself, is someone helping others to help themselves".

Any activities undertaken aim to maximize the behavioral changes that occur, the activities that occur in the community can be classified into two groups that are therapeutic / clinical and are educationally, in each of its implementation is expected to fellow resident has the skills and specific strategies that can be used to promote a change in the process of group activities. There are several activities performed by the resident and staff in interacting with the aim of maximizing the change in behavior, the device is a process device group (Group Process Tools) is in use in the therapy of peer support (community). The element of peer support approach is onsite as opportunities for recreational activities and prevention of recurrence [11-12].

Individuals who are recuperating from an illness also require social and emotional support that is often difficult they get [13-14]. Individuals who experience dependency are also one of the groups that require special support. Those who need special support for their rejection of them, the shame, and the healing process are relatively long or taste frustration. Poor quality of life that they are natural, they are problematic and awkward to socialize are judged, labeled, and despised [15].

Emotional support between resident work in order to minimize pressure or stress experienced by the individual, forms of emotional support needed by a fellow resident individuals who have low self-acceptance. Given this, the social support plays an important role in the lives of individuals with drug dependence.

Six support socially and emotionally is a process relationships that are formed from the individual to the perception that one is loved and appreciated, cherished, for the assistance of individuals who experience stress in their life, emotional support has several aspects: attachment, social integration, reassurance of worth, reliable alliance, guidance, opportunity for nurturance [16].

Based on the research that has been done by Niken [7] that social support in the form of suggestions, advice, and guidance is a form of social persuasion factors that influence adolescent self-efficacy. 8 also found that individuals are directed to the advice and guidance can improve its ability to help individuals achieve the desired objectives [17].

In the Hall of rehabilitation is still a stigma kind of doctor, nurse, counselor, psychologist, or employees of structural itself which considers that a resident is a person offenders rather than victims who should be in therapy when it was explained that in Article 1 paragraph 13 of Law No. 35 Year 2009 on Narcotics, Narcotic Addict is mentioned that people who use or abuse of Narcotics and in a state of dependence on narcotics, both physically and psychologically. So from that sense, it can be classified two (2) types of Narcotic Addict namely: 1. the people who use the drug in the circumstances of physical and psychological dependence, and 2. those who abuse narcotics in a state of physical and psychological dependence.

Major on duty (MOD) as a companion has a considerable role to change the behavior of the resident hall rehabilitation with the stages of therapy are quite long, there is a lack in which case therapy narcotic anonymous yet gained full potential, narcotics anonymous (NA) is a recovery group with a focus on clean of narcotics. The group is known as "self-help group" Team work is based on the principles of the 12-steps.

Self-help group based on the 12-steps assume that the therapeutic value of one addict helping another addict is without appeal and they can only sustain what they have to give way to others. The "peer support" (peer support) in a self-help group will create a sense of comfort to each of its members so that they become open to the solution offered. Peer support services can be guaranteed the quality and integrity of services to drug addicts' [18].

A user will be more open to solutions provided by other fellow users, because it can minimize the impression of patronizing or judgmental often a communication gap between users and people who are not users, and often the scourge in the recovery process. Although we must acknowledge the success of the recovery program is influenced by various factors, and not all will fit the model of a specific therapy, but so far the approach "peer support" is still considered as a method that is quite successful rescue and restore the lives of thousands and even millions of drug users. 
In other words, the 12-step program is the bond of brotherhood that has the same problem or equation fortune to help each other. Terms of a member are simply their desire to quit. As in NA, cease to have meaning for complete abstinence from any kind of use of narcotics. The uniqueness of this program does not cost anything to be paid by its members.

Members meet regularly to share experiences, strength and hope. The members share the successes and failures experienced in dealing with the problem and about how he lived a productive life because he lives the principles contained in the 12-step program. However, if just following routine meetings alone will not deliver maximum results. Following the meeting is to apply the principles of the 12-steps in daily life.

Based 12-step recovery programs are programs that are universal with one overriding goal of helping the drug addicts who want to get help to quit from the use of narcotics and recovering from addiction. In the process of recovery, there are 3 key things that are not negotiable-bargaining, namely: Honesty, Openness of mind, willingness to change, the third principle is the main requirements in carrying out the restoration abuse and drug dependence. Besides these three things is also a major spiritual principle in the process of growth toward full recovery. Peer support showed a significant growth of the complexity of cognitive, intrapersonal development, interpersonal development, appreciation and awareness of diversity, and communication skills [19].

The function of the 12-steps is to help them to look inside themselves, because in essence comes from the recovery of each individual. Helping them to be aware of what is really going on inside of them, and make them a better understanding of addiction/addiction. "Normal" people (those who are not drug abusers) have difficulties to understand the mind of a drug abuser. Drug abusers will understand each other because they have the same problem as well. This is offered by NA fraternity itself, which provides a comfortable place for drug abusers can share with each other about their addiction and the problems they face in everyday life. Each drug abusers can learn from the experiences of those who have long stay clean and be able to take advantage of the program in which they live. Contact with peer support can reduce the use of narcotics [20].

Actually, this is where the main role of a counselor who used to be drug users who have been through the stages of this experience so that in this phase of a resident to get the confidence to be cured or stopped from narcotics addicted, aspects of spiritual enlightenment and realign who reasoned that only God can we complain and only God can give a person is healing. Of the regular meetings that formed a close bond of brotherhood where counselors and resident can share their experience, strength and hope is hoped that the group can function as a messenger of recovery for those who need them. Currently in rehabilitation centers is still a shortage of which is the absence of basic consoler has the field of religious and psychiatric scientific or minimal counselors never received training and mental behavioral sciences (psychology) so as to help a lot in the recovery process resident.

The life of a person trapped and imprisoned on drugs no matter how hard the people want to be cured. This behavior is cognitively motivated and determined by intention [21]. In the healing process they are trying to fight the desire to use drugs again, resulting in sweaty body chills, joint pain, and boredom in rehab. Various events have identified the role of emotional support fellow victims as a protective factor in the difficulties this is because each of the victims felt they had the same fate as well as the experience is almost similar so there is a sense of mutual help between fellow resident.

The reception environment is the most dominant factor associated with relapse. Support from people nearby that have special meaning, as well as the support of the local community plays an important role. This makes the former abusers feel welcome with intact / what it is that makes their behavior is socially unacceptable and can minimize the recurrence and come back healthy physical, psychological, social, and spiritual/religious. Social support can affect the psychological health and maintain a state of abstinence. Various aspects of social support has been shown to be associated with the recovery and maintain a state of abstinence in patients with dependency.

Survey of the relationship between social support to individuals at the time of curing disease, it was found that people who have social support will be more rapid healing than expected. Social supports can Helpful positively to our health when the individual perceives them as decent support, and according to what people need. Handling is aimed at stopping the bad habit of drug addicts by giving support to the feelings, thoughts, behaviors, and drug addicts' totality of the experience itself. Does not rule out the possibility, even with this approach will be seen the very difficult issues to be dealt with in a period of healing. Social support is needed for the drug addicts who are undergoing rehabilitation in order to have a good quality of life.

\section{CONCLUSION}

Peer support from fellow residents and the support of the MOD very meaningful and helpful resident in the healing process. Many residents who does not know and understand the intent and purpose of the program, so that the misconception of the resident will be peer support program, so that the negative 
emotion that is felt not resident self-efficacy. Until now resident differ out back to his family, without any self-efficacy in resident to escape from drug addiction. This is because not all programs of peer support goes according to established guidelines (walking paper), the language used in walking paper is difficult to be understood by the resident, the rehabilitation period narcotics should be 12 months was shortened to six months using the TC program that is more dominant and the lack of human resources.

\section{REFERENCES}

[1] D. L. Klamen and N. S. Miller, "Integration in education for addiction medicine," Journal of Psychoactive Drugs, vol/issue: 29(3), pp. 263-2, 1997.

[2] A. Bandura, "Social Foundation of Thought and Action: A Social Cognitive Theory," Englewood Cliffs, NJ, Prentice Hall, 1986.

[3] C. C. Abar and J. L. Maggs, "Social influence and selection processes as predictors of normative perceptions and alcohol use across the transition to college," Journal of College Student Development, vol. 51, pp. 496-508, 2010.

[4] M. G. Novik and B. O. Boekeloo, "Comparison of student self-reported and administrative data regarding intercession into alcohol misuse among college freshmen dormitory residents," Journal of College Student Development, vol/issue: 53(6), pp. 797 810, 2013.

[5] J. K. Bates, et al., "Functions of marijuana use in college students," Journal of College Student Development, vol/issue: 51(6), pp. 637-648, 2010.

[6] S. J. Colby, et al., "College students' evaluations of heavy drinking: The influence of gender, age, and college status," Journal of College Student Development, vol/issue: 53(6), pp. 797-810. 2012.

[7] B. E. Perron, et al., "Supporting students in recovery on college campuses: Opportunities for student affairs professionals," Journal of Student Affairs Research and Practice, vol/issue: 48(1), pp. 47-64, 2011.

[8] J. F. Hummer, et al., "Factors associated with general and sexual alcohol-related consequences: An examination of college students while studying abroad," Journal of Student Affairs Research and Practice, vol/issue: 47(4), pp. 427-444, 2010.

[9] M. B. Miles and A. M. Huberman, "Qualitative Data Analysis," California, SAGE Publications, 2000.

[10] M. Saleem, "Perceived Social Support and Clinical Anger among Drug Addicts of Southern Punjab Pakistan," The Islamia University of Bahawalpur, Pakistan, 2013.

[11] L. M. Baker, et al., "General health problems of inner-city city sex workers: a pilot study," Journal of the Medical Library Association, vol/issue: 91(1), pp. 67-71, 2003.

[12] K. S. Harris, et al., "Relapse resilience: A process model of addiction and recovery," Journal of Family Psychotherapy, vol. 22, pp. 265-274, 2011.

[13] T. R. Hess and T. J. G. Tracey, "Psychological help-seeking intention among college Students across three problem areas," Journal of Counselling and Development, vol. 91, pp. 321-330, 2013.

[14] R. J. Lowinger, "College students' perceptions of severity and willingness to seek psychological help for drug and alcohol problems," College Student Journal, vol/issue: 46(4), pp. 829-833, 2012.

[15] E. M. Maccio and J. T. Schuler, "Substance use, self-esteem, and self-efficacy among homeless and runaway youth in New Orleans," Journal of Child Adolescent Social Work, vol. 29, pp. 123-136, 2012.

[16] C. E. Curtona and Russell, "The Provisions of Social Relationships and Adaptation to Stress," Advances in Personal Relationships, vol. 1, pp. 37-6, 1987.

[17] N. Widanarti, "Relationship between Family Support with Self Efficacy on Adolescent di SMU Negeri 9 Yogyakarta," Journal Psikologi, vol. 2, pp. 112-123, 2002.

[18] E. Burden, et al., "Developing an Accreditation System for Organizations and Programs Providing Peer Recovery Support Services," Washington, DC, Faces and Voices of Recovery, 2012.

[19] K. H. Heys and M. R. Wawrzynski, "Male peer educators: Effects of participation as peer educators on college men," Journal of Student Affairs Research and Practice, vol/issue: 50(2), pp. 189-207, 2013.

[20] J. W. LaBrie, et al., "Mental and social health impacts the use of protective behavioral strategies in reducing risky drinking and alcohol consequences," Journal of College Student Development, vol/issue: 50(1), pp. 35-49, 2009.

[21] A. Bandura, "Health promotion from the perspective of social cognitive theory," Psychology \& Health, vol. 13, pp. 623-649, 1998. 